\title{
Interdisciplinary systemic juridical argumentation:A new way to base of way contundent and effective
}

\begin{abstract}
The article discusses the interdisciplinary systemic legal argumentation. We propose to elevate the legal argumentation to a complete and integral level (using for it, the totality of the juridical system and the sciences and disciplines different to the law). That is, provide a type of tool that facilitates and ensures a complete and complete analysis, and a basis to achieve in a strict sense, a just, legitimate as expected administration of justice.
\end{abstract}

Keywords: interdisciplinary systemic legal argumentation, legal foundation, systems of administration of justice

\author{
Volume 6 Issue 4 - 2018 \\ Jorge Isaac Torres Manrique \\ Legal consultant, Peru
}

Correspondence: Jorge Isaac Torres Manrique, Legal consultant, Peru, Email kimblellmen@outlook.com

Received: May 16, 2018 | Published: July 24, 2018

\section{By way of justification}

The motivation of the present delivery finds ample credibility, basic the capital importance that the argumentation or juridical foundation is charging, not only in the Peruvian State and in the consequent necessity of having enough weapons as necessary, in order to offer and present a very good defence or exposition of what is meant or supported. This, in the context of the prominence or preponderance of oralization or orality principle that embrace the judicial processes involving the New Code of Criminal Procedure, Legislative Decree No. 957 and the New Procedural Law of Labor, Law No. 29497, mainly. However, our proposal is not only circumscribed or oriented, for its application in other judicial processes, but, which also includes the administrative premises. In the same terms, not only does it contain an oral application, since its expression in printed, physical or written form also records feasibility and sufficient utility in terms of recharged or integral argumentation. That is why, to our proposal, the systemic juridical argumentation, we have also called it, interdisciplinary systemic. ${ }^{1,2}$

In addition, oralization or expository character is not only present in the legal rules indicated, so, that it is to be seen that in the various legal proceedings is present a stage of hearing and another trial, to say the least. On the other hand, it is capital to consider that unlike the once positive right of Kelsen (which considered it only as a set of laws, which could even overlap, contradict), we currently have a legal system, which It is presented completely interlaced, complemented and general lines, systematized. Consequently, we consider that in view of precisely what we do in a legal system, it is wrong (to say the least) to act or to base judicial or administrative procedural level, using only a part of it. In this order of ideas, our present proposal has been called: Interdisciplinary systemic juridical argumentation. It should be added that the present proposal of foundation, presents as antecedent to our previous and recent proposal, which we call: "Tetra legal analysis" and that has four levels: legality, constitutionality, conventionality and legitimacy.

\section{Defining the same}

The interdisciplinary systemic juridical argumentation, which we propose in the present opportunity, consists in grounding or arguing in a complete, total, solid and conclusive way. It provides an overloaded protection, in as much, that such form or argumentative structure assures a support that includes the full range of possibilities for this purpose, that is, the totality of sources of law. It conceives the denomination of "systemic", in reason to its permanent interaction between the diverse stages that its complete structure presents / displays. However, it should be noted that although it is true that the aforementioned way of justifying is basically carried out from the land, it does not mean that the approach depletes its actions or nature. Thus, the present type or method of argumentation is also "interdisciplinary", since it also covers the totality of the various sciences or disciplines that are distinct or alien to law. The explanation of why inclusion to them in a legal basis, is based on the fact that in many opportunities the violations or elements in favor (as the case may be), are unique and exclusively in the world of law.

\section{Structure}

First of all, as a prior matter, it is essential to specify that we have proposed our proposal through a structure. However, it must be understood in an andragogical way (explanatory or teaching adults - unlike pedagogical, whose orientation turns out to be of student minors) not only for the purpose of being understood, but also, for its correct usability. In that sense, within the structure of systemic legal argumentation we propose the existence of seven stages or stages, namely: i) Legality, ii) constitutionality, iii) The binding precedents, iv) The other sources of law, v) Conventionality, vi) Interdisciplinary, and vii) Legitimacy. Structure that we develop in the following terms:

\section{The legality}

The present stage is identified and circumscribed in what is regulated in the law. Thus, it is to be seen that the stage of legality is embodied when it is sustained, both to request, demand, decide, among others; in the application of what is prescribed in the legal norm. It should be added that the prevalence of the validity of the law (of the law), materialized in the former State of law.

\section{The constitutionality}

This stage serves as a complement to what is prescribed by law. That is, when the law is not sufficient (as indeed it is), the Political Constitution grants a wider protection to fundamental rights or grants them constitutional rank.

\section{The binding precedents}

The existence of the binding precedents is also capital, since according to the Peruvian Constitutional Court, its expedition nature seizes, it is basilar when:

a. It is evident that the jurisdictional or administrative operators are resolving with different conceptions about a certain juridical 
figure or against a modality or type of cases; that is, when the existence of conflicting or contradictory precedents is proven;

b. It is noted that jurisdictional or administrative operators are resolving based on an erroneous interpretation of a norm of the constitutionality block; which, in turn, generates an undue application of the same;

c. The existence of a normative vacuum is verified;

d. The existence of a rule lacking of jurisdictional interpretation in the broad sense applicable to a case applicable to a specific case is demonstrated and where there are several interpretative possibilities; and,

e. There is a need to change the binding precedent.

In following that order of ideas, it is evident that for a better and uniform administration of justice and corresponding safeguarding of fundamental rights, both the Law and the existence of the political constitution, are not enough, they do not reach, then, they are insufficient.

\section{The other sources of law}

In this stage are included: jurisprudence, doctrine, legal custom and general principles of law. It is known that the application of the sources of law, register a priority to observe. Then, we should note that the sources of law play an important role, meanwhile, making it possible to complete the scope or, failing that, operate before what is not provided by the Law, the political constitution and the binding precedents.

\section{The conventionality}

In principle, it must be borne in mind that the Fourth Final and Transitory Provision of the Political Constitution teaches: "The rules relating to the rights and freedoms that the Constitution recognizes are interpreted in accordance with the Universal Declaration of Human Rights and with treaties and international agreements on the same matters ratified by Peru. "In addition, refer that Article V.-, Preliminary Title of the Constitutional Procedural Code, regarding the Interpretation of Constitutional Rights, advocates:

The content and scope of constitutional rights protected by the processes regulated in this Code should be interpreted in accordance with the Universal Declaration of Human Rights, the treaties on human rights, as well as the decisions adopted by the international tribunals on human rights constituted according to treaties of which Peru is a part.

Consequently, given that Peru has ratified the American Convention on Human Rights, its application becomes mandatory. It is worth mentioning that the scope and interpretation of fundamental rights, which makes possible the American Convention on Human Rights, are broader than those contained in the Political Constitution and in the jurisprudence of the Constitutional Court not only Peruvians.

Needless to add, that the preponderance of application of constitutionality, binding precedents, other sources of law and conventionality, characterizes the guidelines of a constitutional State of law, which purposefully corresponds to the type of current State, which governs our current legal system.

\section{The interdisciplinary}

However, almost exhausted the legal analysis, for purposes of foundation in a schematic way, it should be noted that the various cases presented, not only embrace considerations pertaining to the world of law, but also, nature of additional disciplines and sciences. Then, verbi gratia it is understood that postulates or principles of engineering, biology, economics, among others, may be present. This is based on the fact that the mere perspective of the law is not enough to achieve the much desired justice for each specific case. It should also be noted that what this stage involves is an analysis of the whole case, but in the light of a discipline and science different from the law. In this sense, the distance of the expertise activity is insufficient, since it only addresses an established or required point or purpose -it does not enter to carve all the disciplines or sciences- therefore, we decided to name this section, as the one of: Interdisciplinary.

\section{The legitimacy}

The present stage, also known as fairness or justice, is the last stage, which completes our proposal of argumentation or interdisciplinary systemic juridical foundation. That is what we should finally aspire to arrive, that is, not only to a decision or foundation that is based on the law, Political Constitution, Binding Precedents, other sources of law, conventionality and Interdisciplinary, but also, in justice. Then, after the sound and strict analysis of the six previous stages, we will be able to determine the fairness in our support, pretension, decision, among others. Likewise, we consider it appropriate to refer to restorative justice, as it currently has great acceptance and application in many countries of the world (which we greatly welcome).

However, it merits to record that it involves the embrace of a justice in accordance with the principles of restoration not only of the aggrieved (the same can be said about constitutional justice, that is, that understands justice from a constitutional perspective). Currently, restorative justice is constituted in the closest to the conception of justice proper. On the other hand, we point out that restorative justice becomes like the other Fourth Wave, because of its relation in the issue of the enumerative place that evokes the so-called Fourth Wave, which is characterized basically by artificial intelligence and the interface between nanotechnology and synthetic biology. By the way, it is worth remembering about the previous three waves, that the first was characterized by agricultural revolution, the second by the industrial revolution, and the third by the information and technological development that ended up leaving hands to strangers.

The first other wave would be, private justice, also called private revenge or state of nature, that characterized by justice done by the affected person's own hand. The second other wave, is the rule of law, which is the right (and not the persons) is who takes the reins of the administration and organization of power. Specifically, it is the law that has the respective protagonism. We estimate that the third other wave is the one where the law no longer governs, but rather the constitution, generating that all the normative apparatus of a State, align or register unavoidably in tune with the provisions of the Political Constitution. It is called: Constitutional State of Law. Incidentally, the present wave is the one that currently governs us and we find ourselves.

Likewise, we point out that the other fourth wave, called: Restorative Justice, is the one that is characterized by strengthening or humanizing the mandates of the Political Constitution. That is, to ensure that the eventual violation of fundamental rights is duly compensated, restored, rebuilt, restored. Thus, to the state policy applied in accordance with restorative justice, we have called it the Restorative State of Law. The one that would soon be materializing. In that order of thought, we consider that the fifth and last other wave, would be that State policy where justice rises above all the legal system. We have called it the following: State of Justice, that is, when 
conflicts are decided or resolved, only in the light of legitimacy or fairness. However, we are that for his eventual arrival we would have to wait not a few decades, centuries, maybe more.

\section{About your application}

This section is perhaps the most important one in this proposal. Because it is here that we explain about the way to approach what concerns its application and we do it in the following terms:

In the first place, it is necessary to set aside preconceived ideas or convictions about the construction of the respective interdisciplinary systemic juridical argumentation to be applied to the specific case. This is because we certainly consider that assume an initial position, when not yet have developed all the stages that contain this type of argument - that is, the seven contained and observing in strictu sensu, the order referred to: i) Legality, ii) Constitutionality, iii) The binding precedents, iv) The other sources of law, v) Conventionality, vi) Interdisciplinary and vii) Legitimacy. We point out that the order of unraveling must be strictly observed, given that the present type of argumentation that we postulate presents in its structure a sequence of ascending progressive analysis. So, we have to mention that what has to be done in principle, is to analyze the case from the point of view of legality. This involves determining if the resolution, demand, etc., is in accordance with the provisions of the law of the matter. If we do not adjust to this, we will first have arrived at the conviction that this document becomes illegal, for example.

In the same way, it will have to go forward with the other stages of the corresponding structure of this argumentative form. Only then, at the end of it, we can arrive at the clear and conclusive conclusion, that said case observes or it is equal with: legality, constitutionality, binding precedents, and other sources of law. But, nevertheless, it does not observe: conventionality, interdisciplinary and justice. So, it is in this sense that we have the basilar structuring of our interdisciplinary systemic juridical argumentation, that is, to explain fundamentally, with which of the seven stages of the same the respective case or document meets and which do not. Thus, the judge will be asked to notice this before issuing his ruling (it is clear, before an approach of such nature, a kind of "seven pack", it should be manifested in such extremes and scope). However, it should be noted that the only way to determine this - that is, to conclude that what you want to substantiate (for or against), complies with any or none of the seven stages indicated and in a very extraordinary way, with the whole of stages- is precisely to finish developing the foundation of the seven stages. It is only there, that it will be able to be evidenced if it is the case, in which stage of them the postulates of justice were reached or perhaps, in none.

For example, in any case it can be determined that after exhausting the respective analysis for the required argumentation, the violations cover not only legal grounds -in strict order of application: i) Legality, ii) The constitutionality, iii) The precedents binding, iv) Other sources of law, and v) Conventionality - but also of another discipline or science, or more than one. It is then that we must give way to the application of interdisciplinary (phase six). And it is at this point, it is necessary to determine whether the principles or postulates of the administration are also observed or not, to cite one of them. Then, if it is the case (that is, when appropriate), it may be noted that the previous situational diagnosis may not have been made, the objectives and results have not been established, and even a budget item has not been foreseen for the required purpose. It is noteworthy that the use of interdisciplinary does not necessarily require the intervention or analysis of the totality of disciplines or sciences of human knowledge, since, certainly, it would become impracticable. For this reason, we consider that according to the nature of each case, the presence of one or more disciplines or sciences, additional to the law, could be noticed, to which to appeal.

After having concluded the development of the elucidation of the stage called: interdisciplinary, it is only when we will be able to establish if it was observed or not (both to demand, answer or sentence) each of the six stages mentioned and also, the proper of the seventh and last, which is fairness, legitimacy or justice. It is then, that with legitimacy we finally arrive or accede to a complete, panoramic view, which will allow us to be aware of what the embrace of justice actually entails. In this sense, in this last stage we can establish whether access to justice was granted or allowed, in any stage (s), or perhaps, in any of them.

\section{How it has been using legal argumentation?}

The present point becomes capital, insofar as it constitutes a very relevant subject of the justification of our present proposal. And, we have observed that both judicially and administratively, it is assumed almost unanimously (at the structural level), at most or at best, four stages - that is, legality, constitutionality, binding precedents and other sources of the right - leaving aside the remaining three - that is, conventionality, interdisciplinary and legitimacy or fairness. Thus, two separate writings are presented, incompletely containing a forceful and effective argument, such as the one that corresponds to our proposal to which we have called: interdisciplinary systemic legal argumentation.

\section{What is offered to the defendant or administered?}

This section is very important, while the defendant is offered, both administrative and judicial, a response to your request, but basically in terms of legality, constitutionality and binding precedents. Then, we have in short, what is offered is a supposed legal justice (adjusted to the provisions of the law), a constitutional justice (which encompasses what is recommended in the Constitution) and, where appropriate, a precedent binding justice (who will scrupulously observe the recorded one or several binding precedents); But in no way in terms of conventionality, interdisciplinary and fairness, legitimacy or justice itself.

\section{What is it that the justiciable or managed expects to be granted? What should be granted?}

We believe that it is logical, that the justiciable or managed to wait for a response from the administration of justice (of the actors of the same) and public and private administration, precisely in terms of justice, that is, that grant what is due and not only what the law, the political constitution, binding precedents and other sources of law have.

The explanation lies in the definition of the word: Justice: that equal to with giving each one what corresponds to him. Justinian pointed to it as: "Justice is the constant and perpetual will to give each one his right". By the way, unlike the meaning of Law:

It is a legal system or system of mandatory norms, systematically hierarchized, that regulate the development of human life in society. It is an art, a discipline that creates, develops, interprets, legal orders 
and principles. It is no longer a mere set of rules (positivism), nor was it or does it have the character of science.

Consequently, it is clear that the definition of Justice is different and difficult to arrive, compared to the Law. In this regard, it is worrisome to note that in many opportunities, some colleagues and students of the faculties of: Law, equate or treat as synonymous to the terms: Law and Justice.

And is that not necessarily the law, the political constitution, the binding precedents and other sources of law, embrace or come to reach the goal that justice requires to be such. In this regard, we argue that what the justiciable or managed and what should be given, is precisely Justice and not Law alone. We do not affirm that the meaning of law is harmful or wrong, we only say that it is different, unlike that of Justice, which turns out to be much broader and healthier, for the purpose of this present work, which involves a total or integral argumentation or justification, forceful and effective.

\section{What we propose with the interdisciplinary systemic legal argumentation?}

In principle, we discard outright the mere legal hyperargumentation, repetition or bulging of it. What we propose is to elevate the legal argument to a complete and integral level. That is, to provide a kind of tool that facilitates and ensures a complete and complete analysis and foundation, in order to achieve a due as expected justice administration, in justice proper. This, in the understanding that justice not only concerns the world of law, but also, in a complementary manner, that of other disciplines and sciences of human knowledge.

\section{Conclusion}

a. The systemic and interdisciplinary juridical argumentation is a legal argumentation strategy that contains as a course, the solid, integral and complete embrace, in order to seek to embrace the long-awaited justice.

b. All stages do not apply to all cases. However, in order to determine in what measure of the same and in what specific cases, it is essential to apply all of the seven steps or stages of the systemic and interdisciplinary legal argumentation.

c. With its application avoids lawsuits, defenses and sentences (as well as, its correlate in administrative headquarters) merely legalists, constitutionalists and conventionalists, who are unaware of the principles of justice. d. We consider that the present scope of our proposal, that is, the systemic and interdisciplinary juridical argumentation, constitute a path, a starting point, more, in any way of arrival. This is, one point of view and one way, the only point of view.

e. Then, the transcendence of the systemic and interdisciplinary juridical argumentation, lies in the constant need to search for a better way to base, be an effective guarantor of the defense and validity of fundamental rights.

\section{Suggestions}

a. We consider first order, preferring the arrival of justice as the north of the administration of justice, putting it before any other kind of consideration.

b. Urge the discussion, debate, promotion, dissemination and adoption of the systemic and interdisciplinary legal argumentation, in the levels of pre and post grade and also in the exercise of advocacy.

c. We propose the creation of multidisciplinary and systemic courts.

d. We also suggest the creation of multidisciplinary and systemic legal studies.

e. Confucius said: "It is better to light a candle than to curse the darkness". In this regard, we propose enlightenment and advancement, instead of conformism and involution. Especially in a subject as relevant as sensitive, as is the legal argument in the administration of justice.

\section{Acknowledgements}

None.

\section{Conflict of interest}

The author declares no conflict of interest.

\section{References}

1. Garrido Koechlin, Juan José. La cuarta Ola. En línea: Recuperado en fecha 2018, de Diario Peru21 Lima.

2. Torres Manrque. Jorge Isaac. Análisis acerca de derecho constitucional contemporáneo. Ediciones Jurídicas de Santiago. Santiago de Chile, 2017. 